\title{
Review \\ Neuroprotective Role of Hypothermia in Acute Spinal Cord Injury
}

\author{
Hasan Al-Nashash ${ }^{1}$ (D) and Angelo H. ALL ${ }^{2, *(D)}$
}

1 Department of Electrical Engineering, College of Engineering, American University of Sharjah, Al Sharjah 46831, United Arab Emirates; hnashash@aus.edu

2 Department of Chemistry, Faculty of Science, Hong Kong Baptist University, Kowloon Tong 999077, Hong Kong

* Correspondence: angelo@hkbu.edu.hk; Tel.: +852-3411-5956

Citation: Al-Nashash, H.; ALL, A.H. Neuroprotective Role of

Hypothermia in Acute Spinal Cord Injury. Biomedicines 2022, 10, 104.

https://doi.org/10.3390/

biomedicines10010104

Academic Editor: Jun Lu

Received: 13 December 2021

Accepted: 30 December 2021

Published: 4 January 2022

Publisher's Note: MDPI stays neutral with regard to jurisdictional claims in published maps and institutional affiliations.

Copyright: (C) 2022 by the authors. Licensee MDPI, Basel, Switzerland. This article is an open access article distributed under the terms and conditions of the Creative Commons Attribution (CC BY) license (https:// creativecommons.org/licenses/by/ $4.0 /)$.

\begin{abstract}
Even nowadays, the question of whether hypothermia can genuinely be considered therapeutic care for patients with traumatic spinal cord injury (SCI) remains unanswered. Although the mechanisms of hypothermia action are yet to be fully explored, early hypothermia for patients suffering from acute SCI has already been implemented in clinical settings. This article discusses measures for inducing various forms of hypothermia and summarizes several hypotheses describing the likelihood of hypothermia mechanisms of action. We present our objective neuro-electrophysiological results and demonstrate that early hypothermia manifests neuroprotective effects mainly during the first- and second-month post-SCI, depending on the severity of the injury, time of intervening, duration, degree, and modality of inducing hypothermia. Nevertheless, eventually, its beneficial effects gradually but consistently diminish. In addition, we report potential complications and side effects for the administration of general hypothermia with a unique referment to the local hypothermia. We also provide evidence that instead of considering early hypothermia post-SCI a therapeutic approach, it is more a neuroprotective strategy in acute and sub-acute phases of SCI that mostly delay, but not entirely avoid, the natural history of the pathophysiological events. Indeed, the most crucial rationale for inducing early hypothermia is to halt these devastating inflammatory and apoptotic events as early and as much as possible. This, in turn, creates a larger time-window of opportunity for physicians to formulate and administer a well-designed personalized treatment for patients suffering from acute traumatic SCI.
\end{abstract}

Keywords: general hypothermia; local hypothermia; spinal cord injury models; neuroprotection; hypothermia mechanisms of action; hypothermia complications

\section{Introduction}

The practical aspects of inducing hypothermia after acute traumatic spinal cord injury (SCI) were adopted many years ago, though its science is not yet fully known. Still, scientists have curious debates whether hypothermia is a myth that gives patients false hope or factual, by which physicians could confidently implement it in their therapeutic approaches. Perhaps hypothermia could become a new standard in treating acute traumatic SCI as one of the potential first treatment steps. To this end, various hypotheses have been investigated to provide definitive answers on the actual short-term and long-term neuroprotective effects of hypothermia [1-4].

In addition to the severity of the primary injury, a few other critical aspects must be considered thoroughly as well. Indeed, the real benefit of hypothermia is a time-sensitive matter. The overall notion of time-dependency benefits of hypothermia includes (i) patient transportation time (how early procedure can start), (ii) how fast the cooling induction should be, (iii) what the lowest therapeutic temperature should be and for how long, and (iv) how slow the re-warming process (to $37^{\circ} \mathrm{C}$ ) should be administered [2,5-7]. Clinical 
scientists agree that perhaps hypothermia does not have any significant neuroprotective role in patients with chronic (years) SCI, nor will it be very effective if the hypothermia starts late during the chronic (tertiary) phase of SCI $[7,8]$. The other critical aspect is how the hypothermia should be administrated, namely: general or local; invasively, minimally invasively, or non-invasively $[1,2,5,9]$. This is because the hypothesis behind their mechanisms of action and their beneficial effects as well as potential complications are entirely different [10]. Indubitably, the deciding factors for choosing the type of hypothermia induction also depend on other underlying clinical conditions of patients.

Nonetheless, another critical aspect to consider is whether inducing moderate but prolonged (e.g., $31-34{ }^{\circ} \mathrm{C}$ for 4-8 h) hypothermia is more effective than a more aggressive reduction in temperature but for a shorter time (e.g., $28-31{ }^{\circ} \mathrm{C}$ for $1-3 \mathrm{~h}$ ). Of course, inducing hypothermia as treatment in SCI patients should be personalized considering the severity of the injury, complications, existent of other pathologies, etc. However, evidence points to the fact that overall mild hypothermia for a short time or severe hypothermia for a longer time would not be preferable. Hence, the aim has often been to induce more moderate but prolonged hypothermia. Moreover, it has also been demonstrated that the early induction of non-invasive moderate hypothermia in patients with traumatic injury (with or without the SCI) will not cause any harm [5,6].

Thus far, nearly all the situations mentioned above have been investigated and been demonstrated that early hypothermia provides the highest neuroprotection post-acute SCI [1,2]. Moreover, it has also been argued that the risk of developing more severe complications is relatively higher in general than the local hypothermia [11,12].

In this paper, we describe alternative forms of hypothermia and discuss various possible hypotheses regarding its mechanisms of action. We also report complications and side effects of general hypothermia and compare it to local hypothermia. In addition, we provide results indicating whether early hypothermia could be considered neuroprotective in acute and sub-acute phases of SCI and for how long.

\section{Hypothermia Induction}

There are mainly two approaches for inducing hypothermia: general and local, and three modalities: invasively, minimally invasively, and non-invasively. Here, we describe the four major types of hypothermia.

\subsection{Non-Invasive General Hypothermia}

This is a straightforward procedure in which the entire body's temperature is reduced. Spraying a mixture of an equal volume of $70 \%$ alcohol and $10{ }^{\circ} \mathrm{C}$ cold water and using a small fan for blowing cool air on the surface of the entire rodent wet body will gradually reduce the temperature $[1,5]$. There are mainly three steps to induce general hypothermia: safely reducing body temperature by $1{ }^{\circ} \mathrm{C}$ every $3-5 \mathrm{~min}$ (often from $37^{\circ} \mathrm{C}$ to $32^{\circ} \mathrm{C}$ ), then keeping constant the low temperature for about $120 \mathrm{~min}$ (though maintaining it for an even longer time is easily feasible), and finally slow re-warming $1^{\circ} \mathrm{C}$ every $5-7$ min to $37^{\circ} \mathrm{C}$. A rectal probe measuring core body temperature provides the feedback necessary to manage body temperature reduction by cold mix spray and fan blow. The re-warming, which is a very critical step, is performed by slowly increasing the temperature of the underneath heating-pad. Nevertheless, since the temperature of all organs will be reduced and then re-warmed, some severe complications are expected and, unfortunately, are inevitable. It is also important to mention that, although the core body temperature could be maintained at $32{ }^{\circ} \mathrm{C}$ without major variations, the internal organs (spinal cord, brain, etc.) may have deviation up to $+/-2{ }^{\circ} \mathrm{C}$.

\subsection{Invasive General Hypothermia}

This method has been used in clinical research settings. The hypothermia is delivered intravascularly via inserting a catheter in the femoral vein. An example of such a catheter is Quattro ${ }^{\circledR}$ Intravascular Heat Exchange Catheter (Custom Luer Model IC4593/8700- 
0783-01). A critical advantage of this technique is that it can be performed soon after the patient is admitted. The cooling rate is approximately $0.5^{\circ} \mathrm{C} / \mathrm{h}$, and the target temperature is often moderate hypothermia at $32-34{ }^{\circ} \mathrm{C}$, which can safely be kept for a long time, even up to $48 \mathrm{~h}$. The re-warming rate to $37{ }^{\circ} \mathrm{C}$ is critical and is set very slowly at about $0.1^{\circ} \mathrm{C} / \mathrm{h}[3,13,14]$. Although managing potential complications is easier than non-invasive general hypothermia, there will still be inevitable risks and other practical limitations. In addition, the internal organs may have $+/-1^{\circ} \mathrm{C}$ deviation as well.

\subsection{Invasive Local Hypothermia}

This is possibly the least desired method to induce hypothermia because of the risks and complications of surgical procedures, though it provides a well-controlled temperature reduction restricted to the region of interest [15]. One of the techniques used to induce local hypothermia invasively in rodents is by performing a larger than usual laminectomy at the site of SCI and without opening the dura, continuously delivering drops of cold water to the opening site, and gently aspirating them from the opposite side. By controlling the temperature of the water and the circulation time, reaching, and maintaining the desired temperature is easily feasible for even a long time. However, this is considered not practical in clinical settings because of potentially serious complications such as bleeding, infection, cord compression by the weight of water, etc. This model was primarily used in rodent experiments for the cell, molecular, and histopathological examinations of the spinal cord after hypothermia, and rodents were intended to be euthanized within the $12 \mathrm{~h}$ post-SCI.

\subsection{Minimally Invasive Local Hypothermia}

As we described it in detail [9], inducing minimally invasive local hypothermia is easily achievable by using a "heat-exchanger", which is comprised of a $12 \mathrm{~cm}$ length Mshaped $2 \mathrm{~mm}$ diameter copper tube and a peristaltic pump [2,5,6,9]. The surgical procedure is minimally invasive and involves a $1 \mathrm{~cm}$ transverse incision of the skin at the site of SCI and making a narrow tunnel simply by inserting the index finger under the skin. This model does not require any form of laminectomy. The center of the M-shaped tube is placed over the epicenter of the injury site (just under the skin), and then secured to the skin by small single sutures. Then, the two extremities of the M-shaped tube connected to the peristaltic pump to circulate cold water $\left(17^{\circ} \mathrm{C}\right)$ at the rate of $129 \mathrm{~mL} / \mathrm{min}$. By adjusting the water temperature and water circulation speed, any target temperature can easily be reached and maintained for a long time. Remarkably, the system will not make any contact with the spinal cord tissue and could selectively reduce the temperature of only a few underneath spinal cord segments slowly, safely, and non-invasively. Simultaneously, the temperature of the core body, the spinal cord, and paravertebral muscles of the target regions could continuously be monitored via microprobe thermocouples to establish a feedback system for the peristaltic pump function rate and control of the hypothermia temperature precisely. The same heat-exchanger system can also be used to slowly re-warm the spinal cord to $37{ }^{\circ} \mathrm{C}$ efficiently. This system allows for the highest precision and complete control of administrating the cooling phase, reaching, and maintaining the target temperature, and the re-warming phase. It carries very minimal risks and is without major complications. It can safely, efficiently, and cost-effectively be implemented in clinical settings as well.

\section{Early Hypothermia: Potential Mechanisms of Action}

Although there are various hypotheses, and each one theoretically provides pieces of evidence for the neuroprotective effect of hypothermia, no consensus regarding hypothermia mechanisms of action has been assented yet. Hypothermia may slow the metabolism, decreasing the need for oxygen and glucose consumption in the tissues. This would reduce the risk of energy failure and in turn, reduces the risk for loss of neural cells. It was also reported that hypothermia would significantly reduce the release of excitotoxic neurotransmitters and the formation of free radicals. Both mechanisms have critical roles in the survival of the neural cells and preservation of the parenchyma. On the other 
hand, if hypothermia is initiated during the very early acute phase of injury, it may also inhibit pro-inflammatory and apoptotic pathways, consequently decreasing the edema, reducing the inflammation, and lowering blood volume at the injury site. These elements play an essential role in stabilizing the blood-spinal cord barrier and render the desired neuroprotective effects $[1,3,4,10,11]$.

Since electrical conduction (action potential generation) and propagation (sequential depolarization and hyperpolarization) are the main functional entities of the neurons, preventing sustained electrical depolarizations of neuropathways post-injury has also been the focus of many scientists. Hypothermia may prevent sustained depolarizations of understress neuropathways that otherwise would become dysfunctional and, in time, could turn non-functional. This mainly happens in spared fibers that survive the immediate injury impact. Spared fibers are anatomically continued axons that pass through the injury site uninterrupted but are not functional. This has been attributed to the post-injury demyelination process. Injury causes a significant reduction in the in situ oligodendrocytes population, disrupting myelin production and thus, halting the normal myelination process. Periodically stimulating these under-stress neuropathways situated within a hostile microenvironment will prevent their dysfunction and ultimately death. Such neural activity has a pivotal role in preserving the neural circuitry network. We have recently demonstrated the effect of various forms of electrical, magnetic, and optogenetic stimulation on neuronal cell survival and remyelination, using in vitro models [16-18]. It was also demonstrated that combing electrical stimulation and a long-term physical therapy and rehabilitation regimen would produce a vastly superior outcome in SCI patients [19-22]. Overall, the protective roles of early hypothermia post-acute SCI could be listed as follows $[1,4,10,11]$ :

$>$ moderating inflammation;

$>$ decreasing the formation of reactive-astrogliosis;

$>$ preserving the blood-spinal cord barrier;

> slowing metabolism;

$>$ decreasing the formation of free radical;

> protecting against acute axonal degeneration;

$>$ inhibiting excitotoxicity;

$>$ preventing sustained electrical depolarization;

$>$ possible neurogenesis.

\section{General Hypothermia: Potential Complications}

Inducing general hypothermia may also cause major and sometimes severe complications if it is not administered and appropriately governed. For instance, hypothermia causes peripheral vasoconstriction. Although one of the desired effects of hypothermia is to slow the perfusion in and around the contused spinal cord parenchyma, this will also affect kidney perfusion and could eventually be turning into renal dysfunction, in which patients may require strict fluid management. Hypothermia may also cause bradycardia and reduced myocardial contractility, adversely affecting the cardiac output and the blood pressure with a potential risk of cardiac fibrillation. Hypothermia may impair leukocyte phagocytic function and influences immuno-suppression as well. In those cases, controlling possible developments of pneumonia and bacterial infections will be the highest priority. It was also reported that hypothermia could trigger mild coagulopathy and platelet dysfunction with serum $\mathrm{K}^{+}, \mathrm{Mg}^{2+}$, and phosphate decreases. Hypothermia could also increase the solubility of the $\mathrm{CO}_{2}$ in blood and hence decrease the $\mathrm{pCO}_{2}$ and increase the blood $\mathrm{pH}$. Patients during hypothermia may show signs of insulin resistance (hyperglycemia) and exhibit an increased insulin sensitivity (hypoglycemia) during the re-warming period. However, the most critical and life-threatening complication of the general hypothermia would be uncontrollable shivering due to alteration of thermoregulatory defense mechanisms, and if it is not controlled well, it can be fatal [3,4,10-12]. Interestingly, local hypothermia is safer and does not cause many of the general hypothermia complications. Moreover, it was also demonstrated that local hypothermia has better outcomes. This was particularly 
shown in the rodent model of SCI assessed by objective neuro-electrophysiology and motor behavioral examinations (data is presented further) $[2,5,6,9]$.

\section{Spinal Cord Injury Models}

Various reproducible and reliable models of SCI in rodents mimicking the injury in humans with similar anatomopathological characteristics have already been developed. Here, we report four main models used in the basic and translational research.

\subsection{Contusion}

In the contusion model of SCI (e.g., traumas), high energy of impact is delivered to a small area of the spinal cord parenchyma in a very short time, and the impact energy is mostly absorbed by just very few underneath segments. The injury starts from the center Gray matter and appears in the form of the cavities. The size of cavities and the progress of injury to the proximal, distal, ventral, dorsal, and lateral areas are of utmost irregularity and depend on the severity of impact [23-25].

\subsection{Compression}

In the compression model of SCI (e.g., tumors), often, there is low pressure for a more extended time directly on the spinal cord tissue. Because of the nature of this injury, smaller nerves are more vulnerable than larger nerves, and the progress of injury is usually much slower than the contusion model [26-28].

\subsection{Transection}

In the transection model of SCI (e.g., lacerations), penetrating trauma, similar to a shattered bony structure or sharp object, usually causes fragmentation in axons. This will develop into acute axonal degeneration (AAD) injury, followed by Wallerian degeneration (WD) of the involved surrounding axons. The injury progress is predominantly proximal with limited anatomical extension and severe physiological consequences [29-33].

\subsection{Focal Demyelination}

In the experimental autoimmune encephalomyelitis (EAE) model of SCI (e.g., MS), researchers aim to develop focal demyelination injury along the White matter in the CNS. This injury is well-demarcated (usually less than a $\mathrm{cm}$ area) and limited to the target area(s), with little progress over time. In this model, the anatomical structures of axons are essentially preserved, though they are not functional due to the demyelination injury [34-38].

\section{Neuroelectrophysiology Monitoring}

Neuroelectrophysiology is the only "objective" clinical and research tool for the functional assessments of the pathways in the nervous system.

\subsection{Somatosensory Evoked Potential}

Somatosensory Evoked Potential (SSEP) is the electrical activities of the brain used to assess the integrity of ascending sensory neuropathways. It is achieved by electrical stimulation of peripheral nerves (usually Median nerves of the upper limbs and Tibial nerves of the lower limbs) and recording somatosensory signals from the corresponding contralateral cortices. The SSEP measurement is a non-invasive procedure and is performed routinely in clinical settings and in the research models of SCI. It provides objective assessments of the onset, severity, and progress of the injury, as well as the endogenous and therapeutic recovery post-SCI [39-51]. The SSEP has extensively been used to assess stem cell replacement therapy [52-55] as well as plasticity and reorganization of neuropathways $[31,56]$ post-SCI as well.

The SSEP has mainly four (millivolt $\mathrm{mV}$ ) average peaks, and each peak appears at a well-defined (millisecond $\mathrm{ms}$ ) time. Their most prominent signal components are identifiable as first positive peak P1 (at $~ 5 \mathrm{~ms}$ ), first negative peak N1 (at 5-10 ms), second 
positive peak P2 (at 15-25 ms), and second negative peak N2 (at 25-55 ms) post-stimulation. Any signal before the $5 \mathrm{~ms}$ is considered stimulation artifact, and after the $55 \mathrm{~ms}$ is part of the EEG signal. For the analysis, the recorded SSEP signal (between 5 and $55 \mathrm{~ms}$ ) is filtered with a bandpass filter with a bandwidth of $20 \mathrm{~Hz}$ to $1 \mathrm{~K} \mathrm{~Hz}$. Ensemble averaging 100 to 700 sweeps is then used to improve the signal-to-noise ratio and extract the noise-free SSEP signals. Peak detection is then applied to locate the N1, and P2 peaks of the averaged SSEPs. The averaged SSEP signals are then normalized relative to the respective or corresponding baseline signal. This is computed by dividing the N1-P2 peak-to-peak amplitude of the SSEP by the N1-P2 peak-to-peak of the corresponding baseline. For SSEP monitoring, often a mixed flow influx of $1.5 \%$ isoflurane, $80 \%$ oxygen, and room air at a rate of $1.5-2 \mathrm{~L} / \mathrm{min}$ is used. The rodent's mouth and nose are placed within an anesthesia mask, and the mask is connected to a C-Pram circuit designed to deliver and evacuate the gas through one tube. The i.p., i.v., or i.m. anesthesia, such as Ketamine cocktails, is not recommended for the SSEP monitoring because they would suppress the brain activities, and, hence, the detection of the SSEP signals would be more difficult.

\subsection{Motor Evoked Potential}

Motor Evoked Potential (MEP) on the other hand, is the electrical signal response used to assess descending motor neuropathways. It is performed by stimulating (electrically, magnetically, optogenetically, etc.) motor cortices and or other higher structures in the nervous system and measuring the evoked activities in the peripheral descending motor pathways and their corresponding muscles. Similarly, the MEP is a non-invasive procedure that can be employed in the clinical settings as well as rodent model of SCI for longitudinal assessments of motor pathways [57-60]. For the MEP recordings, usually $0.1 \mathrm{ml}$ i.p. injection of Ketamine, Xylazine, and Atropine (7.0-1.0-0.5 cocktail) 15 min prior to monitoring is used and this would be the best choice of anesthesia for MEP monitoring.

\section{Motor Behavioral Examination}

Although various modalities of motor behavior examinations have been developed, the Basso, Beattie, and Bresnahan (BBB) locomotor scale method [61,62] currently is one of the most adopted examinations in evaluating the onset and progress as well as recovery of the SCI in rodents (both in mice and rats). The BBB scoring is rather a subjective evaluation tool and is based on 4 min observation of rat's locomotion in an open field $(90 \mathrm{~cm}$ diameter and $30 \mathrm{~cm}$ wall plastic pool space) by two examiners standing in front of each other. The BBB assessment consists of three phases of early ( 0 to 7 score), intermediate ( 8 to 14 score), and late (15 to 21$)$ recovery scoring, in which 0 means no joint or limb movements and 21 means no locomotion deficit $[1,23,29,30,34,63]$.

It is noteworthy to briefly mention here that although defining the role of hypothermia [64] in protecting the CNS either post-trauma or during surgical procedures (such as oblique corpectomy tumor resection) [65] is crucial, other approaches, such as omega-3 fatty acids [66] treatment post-SCI should also be investigated.

\section{Materials and Methods}

In our studies, we used the NYU-Impactor device, which is a well-established SCI model, to induce moderate contusive $(12.5 \mathrm{~mm}) \mathrm{SCI}$ at T8 in adult $(250 \mathrm{~g})$ male and female rats. Rats were under general gas anesthesia (1.5-2\% isoflurane, $80 \%$ oxygen, and room air delivered by the rodent vaporizer and ventilator) during all the surgical procedures and hypothermia induction phases.

The treatment of rats was strictly according to the guidelines set by our university Institutional Animal Care and Use Committee (IACUC), Neuroscience Research, NIH Guidelines for the Care and Use of Laboratory Animals, and as per our extensive publications.

Here, we report the results for (i) non-invasive $2 \mathrm{~h}$ general hypothermia by spraying a mixture of alcohol/cold water and use of a small fun with feedback from core body temperate measured by a rectal probe and (ii) $5 \mathrm{~h}$ and (iii) $8 \mathrm{~h}$ minimally invasive local 
hypothermia using M-shaped heath-exchanger copper tube placed under the skin above the epicenter of SCI. The rats in the control group had identical anesthesia drug, anesthesia time, and surgical procedures, but they underwent only laminectomy (without any injury) at T8 and had no body temperature manipulation. Rats' longitudinal neuroelectrophysiology assessments were completed under general anesthesia, and the SSEP signals were analyzed offline. Motor behavioral (BBB scoring) examinations were conducted in awake and mobile rats. At the end of experiments, after inducing general anesthesia deeply, rats were euthanized according to the NIH Guidelines.

\section{Results}

\subsection{Inducing Hypothermia is not Harmful}

Our results demonstrated that inducing local hypothermia, even aggressively for a relatively long time, neither cause any adverse effect on the spinal cord or surrounding parenchyma, nor on other parts of the nervous system. Healthy adult male and female rats $(n=15)$ were subjected to $30^{\circ} \mathrm{C} \pm 0.5^{\circ} \mathrm{C}$ local hypothermia at T7-T9 for $5 \mathrm{~h}$ and $8 \mathrm{~h}$, while their core body temperature was maintained at $37{ }^{\circ} \mathrm{C} \pm 0.5^{\circ} \mathrm{C}$. Figure $1 \mathrm{a}, \mathrm{b}$ show the amplitude of SSEPs from control, $5 \mathrm{~h}$, and $8 \mathrm{~h}$ local hypothermia recorded when stimulating left and right hindlimbs, respectively. Figure 1c shows the average BBB scores of the same cohort of rats. Four weeks of longitudinal neuro-electrophysiology SSEP monitoring, and motor behavior BBB examinations showed absolutely no functional deterioration or locomotion deficit.

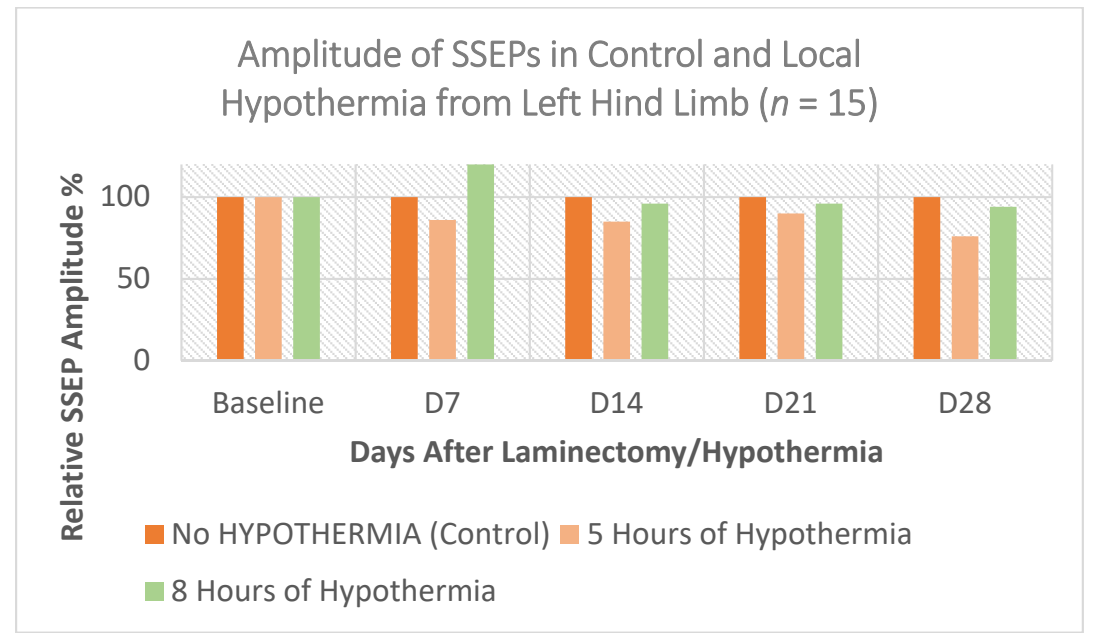

(a)

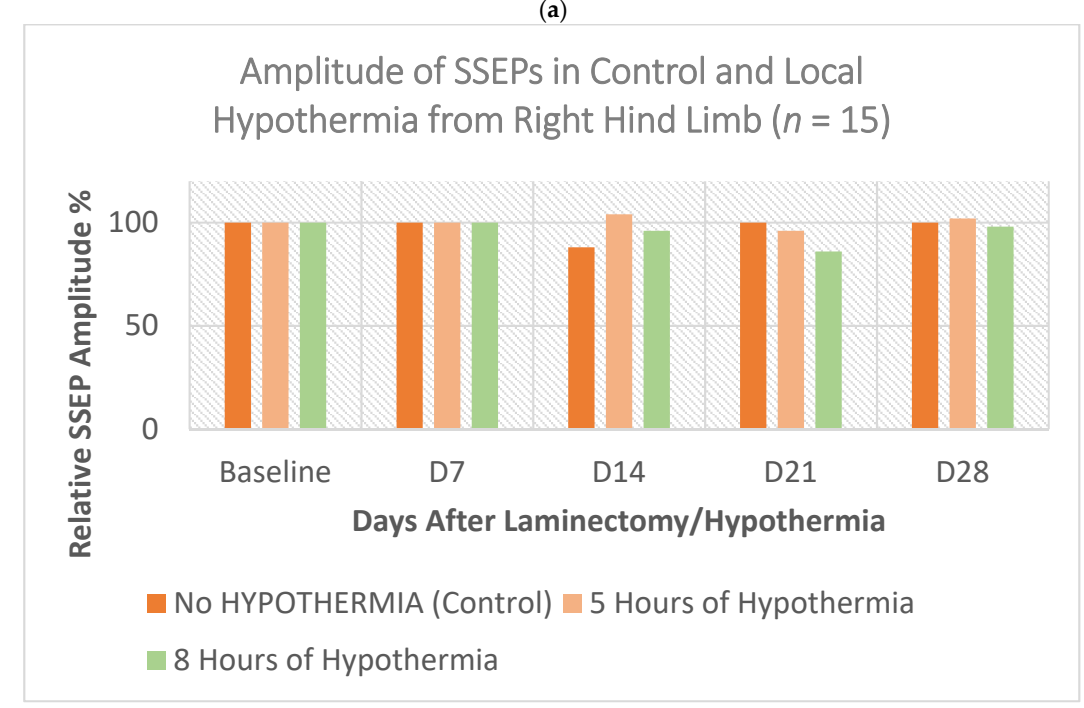

(b)

Figure 1. Cont. 


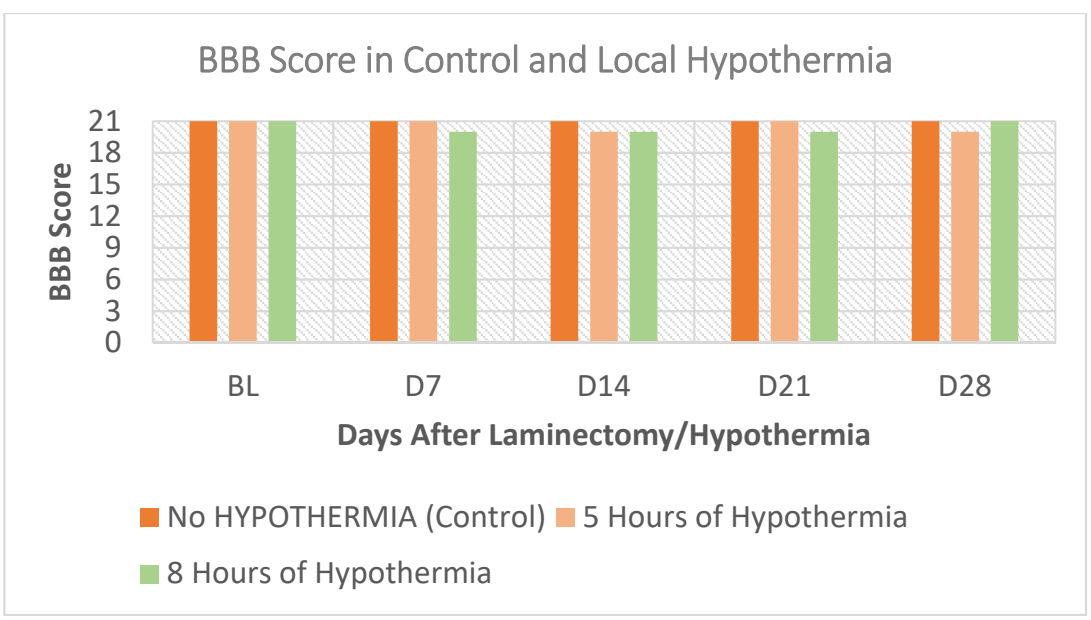

(c)

Figure 1. Shows that prolonged local hypothermia is not harmful $(n=15)$. The three plots show SSEP signals of the left hindlimbs (a) and the right hindlimbs (b) as well as the average BBB scores (c) of rats in normothermia, $5 \mathrm{~h}$, and $8 \mathrm{~h}$ local hypothermia groups.

\subsection{The Temperature Profile of Local and General Hypothermia}

We monitored the profile of temperature changes at the following three sites: spinal cord injury epicenter, cortex (considering the role of tissue continuity and blood circulation on the CNS), and the core body of adult rats $(n=15)$ that underwent moderate $(12.5 \mathrm{~mm}$ NYU-Impactor) contusive SCI. Rats were subjected to either local $30^{\circ} \mathrm{C} \pm 0.5^{\circ} \mathrm{C}$ hypothermia for 5 and $8 \mathrm{~h}$ or general $32{ }^{\circ} \mathrm{C} \pm 0.5^{\circ} \mathrm{C}$ hypothermia for $2 \mathrm{~h}$ and compared to the control (laminectomy without SCI) normothermia $37^{\circ} \mathrm{C} \pm 0.5^{\circ} \mathrm{C}$ group. Practically, during the general hypothermia, the core temperature of rats was successfully reduced to and maintained at $32.1^{\circ} \mathrm{C} \pm 0.4^{\circ} \mathrm{C}$, and during the local hypothermia, the core temperature was successfully maintained at $37.3^{\circ} \mathrm{C} \pm 0.7^{\circ} \mathrm{C}$. As expected, general hypothermia causes a significant reduction in the cortical temperature compared to the effect of hypothermia induction in the spinal cord locally (Figure 2).

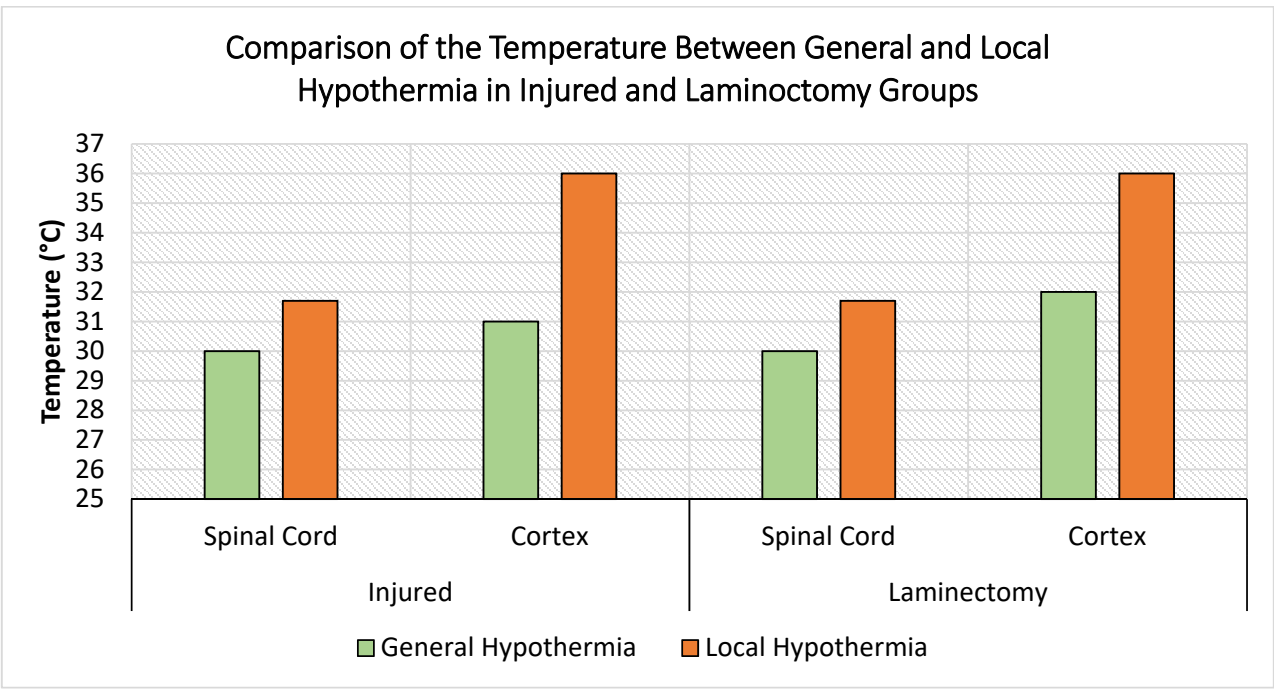

Figure 2. Shows the temperature profiles of rats' cortex and spinal cord parenchyma after induction of general $\left(32 \pm 0.5^{\circ} \mathrm{C}\right)$ and local $\left(30 \pm 0.5^{\circ} \mathrm{C}\right)$ hypothermia in laminectomy (control without SCI) on the right and the injury (moderate contusive SCI) groups on the left. During the local hypothermia, the core temperature was successfully maintained at $37.3^{\circ} \mathrm{C} \pm 0.7^{\circ} \mathrm{C}$. 


\subsection{Hypothermia is Neuroprotective, Though Temporarily}

We investigated the neuroprotective effect of $2 \mathrm{~h}$ general hypothermia at $32{ }^{\circ} \mathrm{C} \pm 0.5^{\circ} \mathrm{C}$ as well as $5 \mathrm{~h}$ and $8 \mathrm{~h}$ prolonged local T7-T9 hypothermia at $30^{\circ} \mathrm{C} \pm 0.5^{\circ} \mathrm{C}$ using the contusive moderate $(12.5 \mathrm{~mm}) \mathrm{T} 8$ thoracic SCI. To reflect the real-life situations, inducing hypothermia was delayed for $2 \mathrm{~h}$ post-SCI induction.

The SSEP results show that the neuroelectrophysiology (SSEPs) improvements of $2 \mathrm{~h}$ general, as well as $5 \mathrm{~h}$ and $8 \mathrm{~h}$ local hypothermia are statistically significant. This, in turn, translates into the neuroprotective beneficial effects of hypothermia. Yet, in all three instances, the improvements were temporary, as depicted in Figure 3a. Similarly to the $2 \mathrm{~h}$ general hypothermia, the $5 \mathrm{~h}$ local hypothermia exhibited the highest neuroprotective effect early, with longer and more prominent efficacy through the 8 weeks of observation. On the other hand, although the $8 \mathrm{~h}$ local hypothermia neuroprotective efficacy remained substantial, it still reduced significantly over the observational time. A similar trend was also noted for the motor behavior examinations and the BBB scores as shown in Figure 3b.

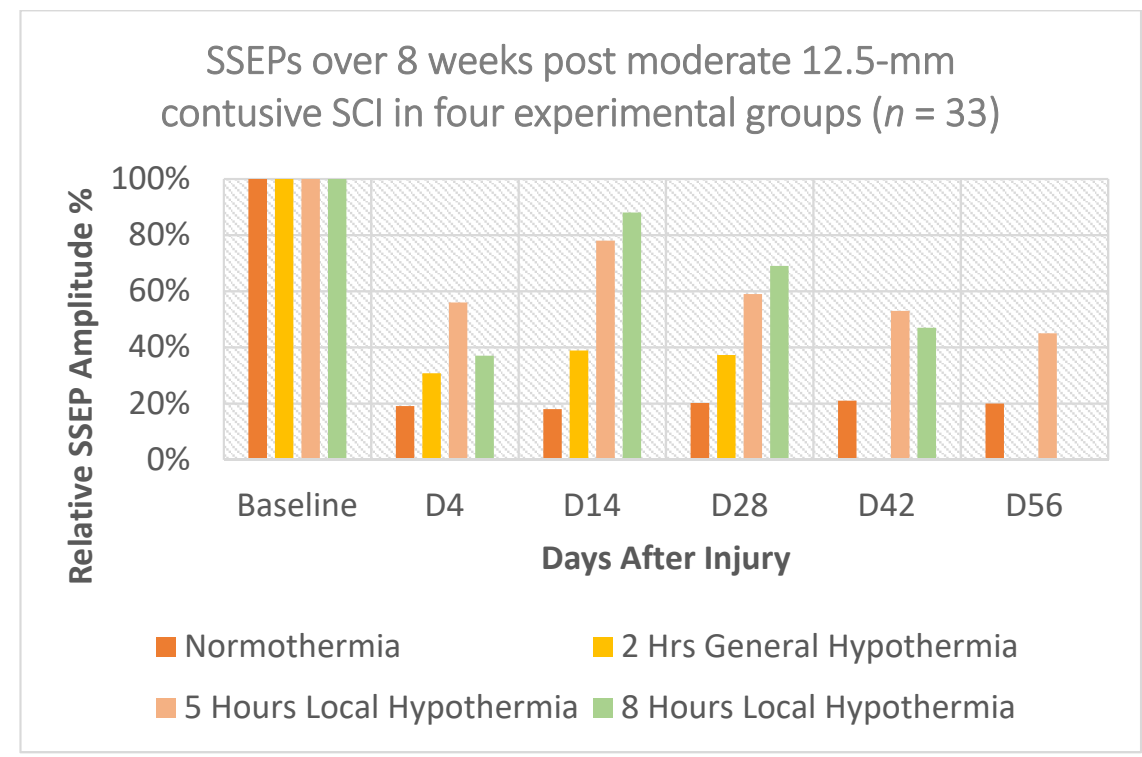

(a)

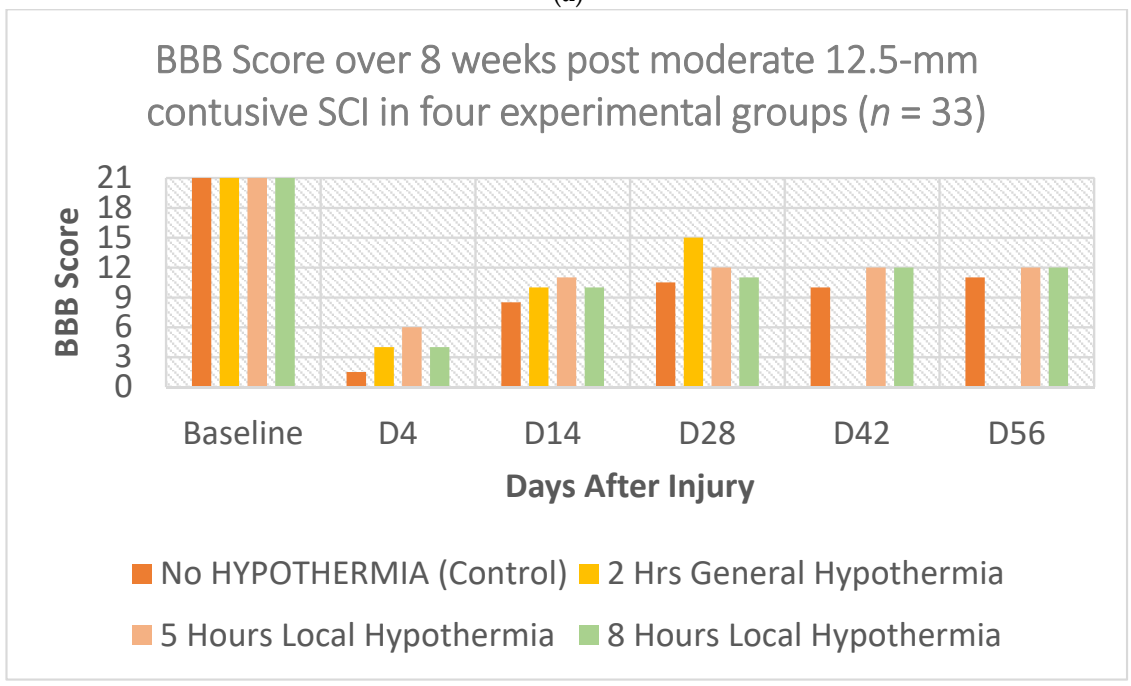

(b)

Figure 3. Shows the (a) SSEP results and (b) BBB scores of normothermia group and the $2 \mathrm{~h}$ general $\left(32{ }^{\circ} \mathrm{C} \pm 0.5{ }^{\circ} \mathrm{C}\right)$ as well as $5 \mathrm{~h}$ and $8 \mathrm{~h}$ local hypothermia $\left(30{ }^{\circ} \mathrm{C} \pm 0.5{ }^{\circ} \mathrm{C}\right)$ in rats with either laminectomy (no injury) or moderate T8 contusive SCI. 
It is important to mention that although the relative amplitude variations in SSEPs between the different hypothermia procedures can reach between $20 \%$ to $40 \%$, these changes do not reflect the same level of improved phenotype outcomes. This is observed in the corresponding BBB score values as well. For example, on Day 14, the difference between SSEPs in normothermia and the $2 \mathrm{~h}$ general hypothermia is almost $20 \%$. However, the BBB score shows a difference of no more than $7 \%$.

\section{Discussion}

Hypothermia treatment as a therapeutic strategy for acute traumatic SCI still brings passionate debates. Scientists continuously evaluate the potential benefits of hypothermia and the characteristics of its various forms of administration. Moreover, the lack of convincing evidence about the probable mechanisms of its action should also be acknowledged. We presented a review of our results to report that early hypothermia is neuroprotective, and its beneficial effects are prominent during the acute and sub-acute primary phase of contusive SCI. Depending on the severity of the injury, such as in the case of moderate injury, its neuroprotection effect could also extend to the secondary phase, but eventually, it fades. Thus, the outcomes of hypothermia induction post-acute moderate and severe SCI (but not necessarily mild and very severe) are very much promising when early results are being considered and analyzed. Yet, analyzing of few weeks later results may not reveal many of the statistically significant differences. Hence, hypothermia should be considered a palliative treatment rather than an actual therapeutic strategy in patients suffering from SCI. In addition, inducing hypothermia may not show neuroprotective effects for mild SCI due to the excellent endogenous recovery or for very severe SCI because of massive destruction of the anatomical structures of the spinal cord. Indeed, hypothermia does not treat the underlying pathological events but would expand and create a larger time-window opportunity for physicians to execute their treatment strategies and rehabilitation therapists to manage their personalized physical therapies for such a staggering time-sensitive disease. In fact, if it is adequately administrated, moderate and local hypothermia has no risk or complications, nor it is harmful. An example is in the case of SCI patients who would be considered candidates for the stem cell replacement trials. Due to the very hostile microenvironment of the spinal cord parenchyma during the primary and secondary phases of SCI, the cells will not likely survive beyond a few days post-transplantation. Early hypothermia not only could prevent some of the destructive inflammatory processes and spare more neuropathways and parenchyma, but also it could improve the microenvironment where the stem cells are intended to be transplanted. Either way, the improvements in functional outcomes during the primary and secondary phases of SCI will be enhanced. Furthermore, considering a different therapeutic strategy, combining early hypothermia with the longstanding rehabilitation regime will undoubtedly improve the quality of life in patients with SCI.

We conclude that hypothermia is neuroprotective and, if applied early, could limit the secondary phase of traumatic spinal cord injury. However, alone, it cannot be considered a solo treatment for SCI per se. We presume the disagreement about the neuroprotective effect of hypothermia among scientists is rooted in whether their conclusion is drawn from early or late results. The early results show that hypothermia is neuroprotective, while for the late findings, the evidence for neuroprotective beneficial effects is not as strong.

Author Contributions: A.H.A. and H.A.-N. contributed to the conception and experimental design; A.H.A. supervised the experimental procedures and provided critical revision; H.A.-N. completed the data analysis; A.H.A. and H.A.-N. drafted the paper. All authors have read and agreed to the published version of the manuscript.

Funding: This study was supported by the Hong Kong Baptist University: Start-Up Tier 1 Fund \# 21.4531.162640 (PI: A. H. All), Faculty Seed Fund \# 31.4531.179234 (PI: A. H. All), Initiation Grant for Faculty Niche Research Areas (IG-FNRA) 2020/21 (PI: A. H. All), and Research Grant Council General Research Fund (GRF) 2021-22 (PI: A. H. All). 
Institutional Review Board Statement: Authors confirm that we followed all the institutional and governmental regulations concerning the ethical use of animals.

Informed Consent Statement: Not applicable.

Data Availability Statement: The data of this study are available from the corresponding authors, Al-Nashash and ALL, upon request.

Acknowledgments: The authors would like to thank colleagues and students for their collaboration and contribution with the experimental procedures.

Conflicts of Interest: The authors declare that do not any conflict of interest.

\section{References}

1. Maybhate, A.; Hu, C.; Bazley, F.A.; Yu, Q.; Thakor, N.; Kerr, C.L.; All, A.H. Potential long-term benefits of acute hypothermia after spinal cord injury: Assessments with somatosensory evoked potentials. Crit. Care Med. 2012, 40, 573-579. [CrossRef] [PubMed]

2. Teh, D.B.L.; Chua, S.M.; Prasad, A.; Kakkos, I.; Jiang, W.; Yue, M.; Liu, X.; All, A.H. Neuroprotective assessment of prolonged local hypothermia post contusive spinal cord injury in rodent model. Spine J. 2018, 18, 507-514. [CrossRef] [PubMed]

3. Dididze, M.; Green, B.A.; Dietrich, W.D.; Vanni, S.M.D.; Wang, M.Y.; Levi, A.D. Systemic hypothermia in acute cervical spinal cord injury: A case-controlled study. Spinal Cord 2012, 51, 395-400. [CrossRef] [PubMed]

4. Wang, J.; Pearse, D.D. Therapeutic Hypothermia in Spinal Cord Injury: The Status of Its Use and Open Questions. Int. J. Mol. Sci. 2015, 16, 16848-16879. [CrossRef]

5. Bazley, F.A.; Pashai, N.; Kerr, C.L.; All, A.H. The Effects of Local and General Hypothermia on Temperature Profiles of the Central Nervous System Following Spinal Cord Injury in Rats. Ther. Hypothermia Temp. Manag. 2014, 4, 115-124. [CrossRef]

6. Vipin, A.; Kortelainen, J.; Al-Nashash, H.; Chua, S.M.; Thow, X.; Manivannan, J.; Astrid; Thakor, N.V.; Kerr, C.L.; All, A.H. Prolonged Local Hypothermia Has No Long-Term Adverse Effect on the Spinal Cord. Ther. Hypothermia Temp. Manag. 2015, 5, 152-162. [CrossRef]

7. Castillo-Abrego, G.A. Hypothermia in spinal cord injury. Crit. Care 2012, 16, A12. [CrossRef]

8. Khan, S.; Plummer, M.; Martinez-Arizala, A.; Banovac, K. Hypothermia in Patients with Chronic Spinal Cord Injury. J. Spinal Cord Med. 2007, 30, 27-30. [CrossRef]

9. Bazley, F.A.; Pashai, N.; Kerr, C.; Thakor, N.; All, A.H. A simple and effective semi-invasive method for inducing local hypothermia in rat spinal cord. In Proceedings of the 35th Annual International Conference of the IEEE Engineering in Medicine and Biology Society (EMBC), Osaka, Japan, 3-7 July 2013; pp. 6321-6324. [CrossRef]

10. Sosnowski, P.; Mikrut, K.; Krauss, H. Hypothermia-Mechanism of action and pathophysiological changes in the human body. Postepy Hig. Med. Dosw. 2015, 69, 69-79. [CrossRef]

11. Díaz, M.; Becker, D.E. Thermoregulation: Physiological and Clinical Considerations during Sedation and General Anesthesia. Anesth. Prog. 2010, 57, 25-33. [CrossRef]

12. Frank, S. Consequences of hypothermia. Curr. Anaesth. Crit. Care 2001, 12, 79-86. [CrossRef]

13. Dietrich, W.D.; Levi, A.D.; Wang, M.; Green, B.A. Hypothermic Treatment for Acute Spinal Cord Injury. Neurotherapeutics 2011, 8 , 229-239. [CrossRef]

14. Levi, A.D.; Casella, G.; Green, B.A.; Dietrich, W.D.; Vanni, S.; Jagid, J.; Wang, M.Y. Clinical Outcomes Using Modest Intravascular Hypothermia After Acute Cervical Spinal Cord Injury. Neurosurgery 2010, 66, 670-677. [CrossRef] [PubMed]

15. Straus, D.; Prasad, V.; Munoz, L. Selective therapeutic hypothermia: A review of invasive and noninvasive techniques. Arq. Neuro-Psiquiatr. 2011, 69, 981-987. [CrossRef] [PubMed]

16. Lee, H.U.; Blasiak, A.; Agrawal, D.R.; Loong, D.T.B.; Thakor, N.V.; All, A.H.; Ho, J.S.; Yang, I.H. Subcellular electrical stimulation of neurons enhances the myelination of axons by oligodendrocytes. PLoS ONE 2017, 12, e0179642. [CrossRef] [PubMed]

17. Prasad, A.; Teh, D.B.L.; Blasiak, A.; Chai, C.; Wu, Y.; Gharibani, P.; Yang, I.H.; Phan, T.T.; Lim, K.-L.; Yang, H.; et al. Static Magnetic Field Stimulation Enhances Oligodendrocyte Differentiation and Secretion of Neurotrophic Factors. Sci. Rep. 2017, 7, 1-12. [CrossRef]

18. Teh, D.B.L.; Prasad, A.; Jiang, W.; Zhang, N.; Wu, Y.; Yang, H.; Han, S.; Yi, Z.; Yeo, Y.; Ishizuka, T.; et al. Driving Neurogenesis in Neural Stem Cells with High Sensitivity Optogenetics. NeuroMolecular Med. 2019, 22, 139-149. [CrossRef]

19. Harkema, S.; Gerasimenko, Y.; Hodes, J.; Burdick, J.; Angeli, C.; Chen, Y.; Ferreira, C.; Willhite, A.; Rejc, E.; Grossman, R.G.; et al. Effect of epidural stimulation of the lumbosacral spinal cord on voluntary movement, standing, and assisted stepping after motor complete paraplegia: A case study. Lancet 2011, 377, 1938-1947. [CrossRef]

20. Rejc, E.; Angeli, C.A. Spinal Cord Epidural Stimulation for Lower Limb Motor Function Recovery in Individuals with Motor Complete Spinal Cord Injury. Phys. Med. Rehabil. Clin. North Am. 2019, 30, 337-354. [CrossRef]

21. Rejc, E.; Smith, A.C.; Weber, K.A.I.; Ugiliweneza, B.; Bert, R.J.; Negahdar, M.; Boakye, M.; Harkema, S.J.; Angeli, C.A. Spinal Cord Imaging Markers and Recovery of Volitional Leg Movement with Spinal Cord Epidural Stimulation in Individuals With Clinically Motor Complete Spinal Cord Injury. Front. Syst. Neurosci. 2020, 14, 559313. [CrossRef]

22. Luo, S.; Xu, H.; Zuo, Y.; Liu, X.; All, A.H. A Review of Functional Electrical Stimulation Treatment in Spinal Cord Injury. NeuroMolecular Med. 2020, 22, 447-463. [CrossRef] [PubMed] 
23. Agrawal, G.; Kerr, C.L.; Thakor, N.; All, A.H. Characterization of Graded Multicenter Animal Spinal Cord Injury Study Contusion Spinal Cord Injury Using Somatosensory-Evoked Potentials. Spine 2010, 35, 1122-1127. [CrossRef] [PubMed]

24. Bazley, F.A.; Maybhate, A.; Tan, C.S.; Thakor, N.V.; Kerr, C.; All, A.H. Enhancement of Bilateral Cortical Somatosensory Evoked Potentials to Intact Forelimb Stimulation Following Thoracic Contusion Spinal Cord Injury in Rats. IEEE Trans. Neural Syst. Rehabil. Eng. 2014, 22, 953-964. [CrossRef] [PubMed]

25. Fatoo, N.; Mirza, N.; Ahmad, R.; Al-Nashash, H.; Naeini, H.; Thakor, N. Detection and Assessment of Spinal Cord Injury Using Spectral Coherence. Annu. Int. Conf. IEEE Eng. Med. Biol. Soc. 2007, 2007, 1426-1429. [CrossRef] [PubMed]

26. Cheriyan, J.; Ryan, D.J.; Weinreb, J.H.; Paul, J.C.; Lafage, V.; Kirsch, T.; Errico, T. Spinal cord injury models: A review. Spinal Cord 2014, 52, 588-595. [CrossRef] [PubMed]

27. Chung, W.-H.; Lee, J.-H.; Chung, D.-J.; Yang, W.-J.; Lee, A.-J.; Choi, C.-B.; Chang, H.-S.; Kim, D.-H.; Chung, H.J.; Suh, H.J.; et al. Improved rat spinal cord injury model using spinal cord compression by percutaneous method. J. Veter- Sci. 2013, 14, 329-335. [CrossRef]

28. Su, Y.-F.; Lin, C.-L.; Lee, K.-S.; Tsai, T.-H.; Wu, S.-C.; Hwang, S.-L.; Chen, S.-C.; Kwan, A.-L. A modified compression model of spinal cord injury in rats: Functional assessment and the expression of nitric oxide synthases. Spinal Cord 2015, 53, 432-435. [CrossRef]

29. All, A.H.; Al Nashash, H.; Mir, H.; Luo, S.; Liu, X. Characterization of transection spinal cord injuries by monitoring somatosensory evoked potentials and motor behavior. Brain Res. Bull. 2019, 156, 150-163. [CrossRef]

30. All, A.H.; Al-Nashash, H. Comparative analysis of functional assessment for contusion and transection models of spinal cord injury. Spinal Cord 2021, 59, 1206-1209. [CrossRef]

31. Vipin, A.; Thow, X.Y.; Mir, H.; Kortelainen, J.; Manivannan, J.; Al-Nashash, H.; All, A.H. Natural Progression of Spinal Cord Transection Injury and Reorganization of Neural Pathways. J. Neurotrauma 2016, 33, 2191-2201. [CrossRef]

32. Al-Nashash, H.; Luo, S.; Liu, X.; All, A.H. Trading baseline with forelimbs somatosensory evoked potential for longitudinal analysis in thoracic transection spinal cord injury. J. Neurosci. Methods 2020, 343, 108858. [CrossRef]

33. Mir, H.; Al-Nashash, H.; Yuan, T.X.; Kortelainen, J.; Min, C.S.; Manivannan, J.; All, A.H. Assessment of bilateral SSEP signals enhancement following transectional spinal cord injury using linear modelling. In Proceedings of the World Congress on Medical Physics and Biomedical Engineering, Toronto, Canada, 7-12 June 2015; p. 1219. [CrossRef]

34. All, A.H.; Agrawal, G.; Walczak, P.; Maybhate, A.; Bulte, J.W.M.; Kerr, D.A. Evoked potential and behavioral outcomes for experimental autoimmune encephalomyelitis in Lewis rats. Neurol. Sci. 2010, 31, 595-601. [CrossRef]

35. Agrawal, G.; Sherman, D.; Walczak, P.; Bulte, J.; Thakor, N.; Kerr, D.; All, A. Shape analysis of Somatosensory Evoked Potentials to detect a focal spinal cord lesion. In Proceedings of the IEEE Northeast Bioengineering Conference, Boston, MA, USA, 3-5 April 2009; pp. 1-2. [CrossRef]

36. Walczak, P.; All, A.H.; Rumpal, N.; Gorelik, M.; Kim, H.; Maybhate, A.; Agrawal, G.; Campanelli, J.T.; Gilad, A.A.; Kerr, D.A.; et al. Human glial-restricted progenitors survive, proliferate, and preserve electrophysiological function in rats with focal inflammatory spinal cord demyelination. Glia 2010, 59, 499-510. [CrossRef] [PubMed]

37. All, A.H.; Walczak, P.; Agrawal, G.; Gorelik, M.; Lee, C.; Thakor, N.V.; Bulte, J.W.; Kerr, D.A. Effect of MOG sensitization on somatosensory evoked potential in Lewis rats. J. Neurol. Sci. 2009, 284, 81-89. [CrossRef] [PubMed]

38. Agrawal, G.; Sherman, D.; Maybhate, A.; Gorelik, M.; Kerr, D.A.; Thakor, N.V.; All, A.H. Slope analysis of somatosensory evoked potentials in spinal cord injury for detecting contusion injury and focal demyelination. J. Clin. Neurosci. 2010, 17, 1159-1164. [CrossRef] [PubMed]

39. Mir, H.; Al-Nashash, H.; Kerr, D.; All, A.; Thakor, N. Using Variations of Somatosensory Evoked Potentials to Quantify Spinal Cord Injury Level. Engineering 2013, 05, 99-102. [CrossRef]

40. Kortelainen, J.; Al-Nashash, H.; Vipin, A.; Thow, X.Y.; All, A. The effect of anaesthesia on somatosensory evoked potential measurement in a rat model. Lab. Anim. 2015, 50, 63-66. [CrossRef] [PubMed]

41. Kortelainen, J.; Vipin, A.; Yuan, T.X.; Mir, H.; Thakor, N.; Al-Nashash, H.; All, A. Effect of isoflurane on somatosensory evoked potentials in a rat model. Annu. Int. Conf. IEEE Eng. Med. Biol. Soc. 2014, 2014, 4286-4289. [CrossRef] [PubMed]

42. Al-Nashash, H.; Fatoo, N.A.; Mirza, N.N.; Ahmed, R.I.; Agrawal, G.; Thakor, N.; All, A.H. Spinal Cord Injury Detection and Monitoring Using Spectral Coherence. IEEE Trans. Biomed. Eng. 2009, 56, 1971-1979. [CrossRef] [PubMed]

43. Agrawal, G.; Sherman, D.; Thakor, N.; All, A. A novel shape analysis technique for somatosensory evoked potentials. Annu. Int. Conf. IEEE Eng. Med. Biol. Soc. 2008, 2008, 4688-4691. [CrossRef]

44. Mir, H.; Al-Nashash, H.; Kerr, D.; Thakor, N.; All, A. Histogram based quantification of spinal cord injury level using somatosensory evoked potentials. Annu. Int. Conf. IEEE Eng. Med. Biol. Soc. 2010, 2010, 4942-4945. [CrossRef]

45. Väyrynen, E.; Noponen, K.; Vipin, A.; Thow, X.Y.; Al-Nashash, H.; Kortelainen, J.; All, A.; Yuan, T.X. Automatic Parametrization of Somatosensory Evoked Potentials with Chirp Modeling. IEEE Trans. Neural Syst. Rehabil. Eng. 2016, 24, 981-992. [CrossRef]

46. Mir, H.; Al-Nashash, H.; Kerr, D.; All, A.; Thakor, N. Spinal cord injury evaluation using morphological difference of somatosensory evoked potentials. In Proceedings of the 5th International Conference on Bioinformatics and Biomedical Engineering, Wuhan, China, 10-12 May 2011; pp. 1-4. [CrossRef]

47. Sherman, D.; Wuyyuru, V.; Brooke, M.J.; Zhang, H.; Sepkuty, J.; Thakor, N.; Natarajan, A.; All, A. Spinal cord integrity monitoring by adaptive coherence measurement. J. Neurosci. Methods 2010, 193, 90-99. [CrossRef] 
48. Mir, H.; Al-Nashash, H.; Kortelainen, J.; All, A. Novel Modeling of Somatosensory Evoked Potentials for the Assessment of Spinal Cord Injury. IEEE Trans. Biomed. Eng. 2017, 65, 511-520. [CrossRef]

49. Mir, H.S.; Al-Nashash, H.; All, A.H.; Thakor, N.V. Quantification of Spinal Cord Injury Level Using Somatosensory Evoked Potentials. In Proceedings of the 4th International Conference on Bioinformatics and Biomedical Engineering, Chengdu, China, 18-20 June 2010; pp. 1-4. [CrossRef]

50. Mir, H.; Al-Nashash, H.; Kortelainen, J.; All, A. Assessment of Spinal Cord Injury via Sparse Modeling of Somatosensory Evoked Potential Signals. In Proceedings of the 2017 Asia Modelling Symposium, Kota Kinabalu, Malaysia, 4-6 December 2017; pp. 13-17. [CrossRef]

51. All, A.H.; Luo, S.; Liu, X.; Al-Nashash, H. Effect of thoracic spinal cord injury on forelimb somatosensory evoked potential. Brain Res. Bull. 2021, 173, 22-27. [CrossRef]

52. Kerr, C.L.; Letzen, B.S.; Hill, C.M.; Agrawal, G.; Thakor, N.V.; Sterneckert, J.L.; Gearhart, J.D.; All, A.H. Efficient Differentiation of Human Embryonic Stem Cells into Oligodendrocyte Progenitors for Application in a Rat Contusion Model of Spinal Cord Injury. Int. J. Neurosci. 2010, 120, 305-313. [CrossRef]

53. All, A.H.; Bazley, F.A.; Gupta, S.; Pashai, N.; Hu, C.; Pourmorteza, A.; Kerr, C. Human Embryonic Stem Cell-Derived Oligodendrocyte Progenitors Aid in Functional Recovery of Sensory Pathways following Contusive Spinal Cord Injury. PLoS ONE 2012, 7, e47645. [CrossRef]

54. All, A.H.; Gharibani, P.; Gupta, S.; Bazley, F.A.; Pashai, N.; Chou, B.-K.; Shah, S.; Resar, L.M.; Cheng, L.; Gearhart, J.D.; et al. Early Intervention for Spinal Cord Injury with Human Induced Pluripotent Stem Cells Oligodendrocyte Progenitors. PLoS ONE 2015, 10, e0116933. [CrossRef]

55. Bazley, F.A.; Pourmorteza, A.; Gupta, S.; Pashai, N.; Kerr, C.; All, A.H. DTI for assessing axonal integrity after contusive spinal cord injury and transplantation of oligodendrocyte progenitor cells. Annu. Int. Conf. IEEE Eng. Med. Biol. Soc. 2012, $2012,82-85$. [CrossRef] [PubMed]

56. Bazley, F.A.; All, A.H.; Thakor, N.V.; Maybhate, A. Plasticity associated changes in cortical somatosensory evoked potentials following spinal cord injury in rats. Annu. Int. Conf. IEEE Eng. Med. Biol. Soc. 2011, 2011, 2005-2008. [CrossRef] [PubMed]

57. Iyer, S.; Maybhate, A.; Presacco, A.; All, A.H. Multi-limb acquisition of motor evoked potentials and its application in spinal cord injury. J. Neurosci. Methods 2010, 193, 210-216. [CrossRef] [PubMed]

58. Agrawal, G.; Iyer, S.; All, A.H. A comparative study of recording procedures for motor evoked potential signals. Annu. Int. Conf. IEEE Eng. Med. Biol. Soc. 2009, 2009, 2086-2089. [CrossRef] [PubMed]

59. Zhang, H.; Oweis, Y.; Mozaffari-Naeini, H.; Venkatesha, S.; Thakor, N.V.; Natarajan, A. Continuous Quantitative Motor Evoked Potentials for Spinal Cord Injury Detection. In Proceedings of the 2nd International IEEE EMBS Conference on Neural Engineering, Arlington, VA, USA, 16-19 March 2005; pp. 430-433. [CrossRef]

60. Bazley, F.A.; Hu, C.; Maybhate, A.; Pourmorteza, A.; Pashai, N.; Thakor, N.; Kerr, C.L.; All, A.H. Electrophysiological evaluation of sensory and motor pathways after incomplete unilateral spinal cord contusion. J. Neurosurg. Spine 2012, 16, $414-423$. [CrossRef] [PubMed]

61. Basso, D.M.; Beattie, M.S.; Bresnahan, J.C. A Sensitive and Reliable Locomotor Rating Scale for Open Field Testing in Rats. J. Neurotrauma 1995, 12, 1-21. [CrossRef] [PubMed]

62. Basso, D.; Beattie, M.S.; Bresnahan, J.C. Graded Histological and Locomotor Outcomes after Spinal Cord Contusion Using the NYU Weight-Drop Device versus Transection. Exp. Neurol. 1996, 139, 244-256. [CrossRef] [PubMed]

63. Agrawal, G.; Thakor, N.V.; All, A.H. Evoked potential versus behavior to detect minor insult to the spinal cord in a rat model. $J$. Clin. Neurosci. 2009, 16, 1052-1055. [CrossRef] [PubMed]

64. Ahmad, F.U.; Wang, M.Y.; Levi, A.D. Hypothermia for Acute Spinal Cord Injury-A Review. World Neurosurg. 2014, 82, 207-214. [CrossRef]

65. Tykocki, T.; Poniatowski, A.; Czyz, M.; Wynne-Jones, G. Oblique corpectomy in the cervical spine. Spinal Cord 2017, 56, 426-435. [CrossRef]

66. Wojdasiewicz, P.; Poniatowski, A.; Turczyn, P.; Frasuńska, J.; Paradowska-Gorycka, A.; Tarnacka, B. Significance of Omega-3 Fatty Acids in the Prophylaxis and Treatment after Spinal Cord Injury in Rodent Models. Mediat. Inflamm. 2020, 2020, 1-11. [CrossRef] 